\title{
Role of the Bronchodilator Test Defined by the Forced Vital Capacity in Chronic Obstructive Pulmonary Disease Phenotyping
}

This article was published in the following Dove Press journal: International Journal of Chronic Obstructive Pulmonary Disease

\author{
Xiaoling Zhang ${ }^{1}, *$ \\ Zhenchao $\mathrm{Wu}^{2-4, *}$ \\ Yi Liu ${ }^{1,2,4}$ \\ Shujuan Jiang ${ }^{1,4}$ \\ 'Department of Pulmonary and Critical \\ Care Medicine, Shandong Provincial \\ Hospital Affiliated to Shandong \\ University, Jinan 25002I, Shandong, \\ People's Republic of China; ${ }^{2}$ Department \\ of Pulmonary and Critical Care Medicine, \\ Shandong Provincial Hospital Affiliated to \\ Shandong First Medical University, Jinan \\ 250000, Shandong, People's Republic of \\ China; ${ }^{3}$ Department of Pulmonary and \\ Critical Care Medicine, The Third \\ Affiliated Hospital of Shandong First \\ Medical University, Jinan 250000, \\ Shandong, People's Republic of China; \\ ${ }^{4}$ Shandong Key Laboratory of Infectious \\ Respiratory Disease, Jinan 250000, \\ Shandong, People's Republic of China \\ *These authors contributed equally to \\ this work
}

\begin{abstract}
Purpose: In clinical practice, some chronic obstructive pulmonary disease (COPD) patients experienced a remarkable increase in forced vital capacity (FVC) after bronchodilator administration, whereas forced expiratory volume in the first second (FEV1) remains substantially unchanged. We assume this may relate to airway inflammatory type. We aim to analyze the clinical characteristics and explore the usefulness of the bronchodilator test, especially FVC, in this new COPD phenotype.
\end{abstract}

Patients and Methods: A total of 346 COPD patients with exacerbation who underwent bronchodilator tests, fractional exhaled nitric oxide (FeNO) measurements and blood eosinophil counts were analyzed. The characteristics, FeNO levels, and blood eosinophil counts were compared between patients with and without significant bronchodilator responsiveness in terms of FVC.

Results: Patients with significant FVC responsiveness displayed poorer lung function and higher FeNO levels compared with those without considerable FVC responsiveness $(\mathrm{Z}=$ -5.042 to $-0.375, \mathrm{p}=0.000-0.022$ ). There is a discernible linear relationship between FeNO levels and FVC responsiveness to bronchodilator use $(\mathrm{r}=0.251, \mathrm{P}=0.001)$. The application of bronchodilator responsiveness of FVC for detecting high FeNO levels in COPD patients exhibited relatively high sensitivity $(61.8 \%)$ and specificity $(86.7 \%)$.

Conclusion: We demonstrated that COPD patients with significant FVC responsiveness had higher FeNO levels than non-responders and established a simple method for detecting high FeNO values. FVC responders may be identified as a separate group of COPD patients.

Keywords: COPD, pulmonary function test, bronchodilator responsiveness, forced vital capacity, fractional exhaled nitric oxide

\section{Introduction}

Chronic obstructive pulmonary disease (COPD) is a disease characterized by persistent airflow obstruction, which is not fully reversible and is usually progressive and is associated with elevated chronic inflammatory responses to noxious particles or gases in the airways. ${ }^{1}$ The prevalence of COPD is skyrocketing, and it is expected to be the world's third most fatal disease by $2030 .^{2}$

COPD is heterogeneous in nature. COPD patients with similar forced expiratory volume in the first second (FEV1) display different clinical manifestations, quality of life, exacerbation frequencies, and responses to treatment. ${ }^{3}$ Nowadays, COPD phenotyping is increasingly becoming a topic of interest to more and more physicians aiming at classifying patients into distinct clinical subgroups to initiate
Correspondence: Shujuan Jiang Email zhangxII20923@I63.com 
appropriate individualized care which may lead to a better prognosis and quality of life for patients. ${ }^{4,5}$

The bronchodilator test plays a crucial role in the management of COPD, eg, the diagnosis of COPD is confirmed in cases with FEV1/FVC ratios below 0.7 after bronchodilator administration. Flow response after bronchodilator inhalation is universally and frequently used as an indicator for assessing responsiveness in general practice. However, in moderate to severe COPD cases, flow response may be poor, yet the response in terms of volume can be relatively favorable, which is probably due to a reduction in hyperinflation. ${ }^{6-9}$ It appears that patients with significant $\mathrm{FVC}$ responsiveness are apt to progress to more severe COPD stages.

Airway hyperresponsiveness is associated with airway inflammatory, especially Th2 cell-induced eosinophilic inflammation. Recent research had proved eosinophilic inflammation dominated COPD is an important COPD phenotype. Its clinical characteristics are airway responsiveness (the change of FEV1), higher eosinophil counts, and higher FeNO concentrations. Although some studies were focused on the role of the change of FEV1 value after bronchodilator inhalation, but there are rarely studies about the role of the change of FVC value in COPD, and we are not clear about the relationship between the change and FeNO or eosinophil.

On these grounds, this study's objectives were as follows: 1) to compare the characteristics of COPD patients classified as FVC responders and non-responders during the bronchodilator test and 2) to evaluate the benefits of the bronchodilator test in terms of FVC in COPD phenotype.

\section{Patients and Methods}

\section{Patients}

A total of 346 patients with COPD exacerbation were sequentially enrolled from June 2017 to August 2019. All patients were outpatients from Respiratory Clinic of Shandong Provincial Hospital. They were definitely diagnosed with COPD by spirometry based on the Global initiative for chronic obstructive lung disease (GOLD 2017) criteria. ${ }^{1}$ COPD exacerbations are defined as an acute worsening of respiratory symptoms that result in additional therapy. ${ }^{1}$ COPD patients simultaneously diagnosed with lung cancer, interstitial pulmonary disease, asthma, bronchiectasis, history of pulmonary resection, or significant comorbidities other than COPD that might influence the ability to perform pulmonary function tests, fractional exhaled nitric oxide (FeNO) measurements and blood eosinophil counts were excluded.

\section{Observational Indicators}

Basic medical information: gender, age, height and weight, smoking history were recorded. Smoking history: patients who still smoking without quitting smoking were defined current smokers; patients who formerly had smoking history, but have quitted smoking more than 3 months were defined ex-smokers.

Exhaled nitric oxide measurements (FeNO): FeNO levels were assessed according to the ATS/ERS guidelines using a NO analyzer (SV-eCO-01, Sunvon, China). ${ }^{10}$ The subjects were informed to deeply inhale NO-free air and immediately fully exhale via a mouthpiece at a constant flow rate $(50 \mathrm{~mL} / \mathrm{s})$ for $10 \mathrm{~s}$. Every FeNO measurement was acquired before the reversibility tests in order to prevent spirometry from influencing the FeNO levels.

Pulmonary function test (PFT): The bronchodilator tests were conducted according to the American Thoracic Society (ATS) and the European Respiratory Society (ERS) guidelines. ${ }^{11-13}$ Patients received good techniqueconducting and tested by a unified and qualified equipment (Master Screen Body, Jaeger, Germany). The second time FVC maneuver was performed, similar to the first one, 15 minutes after the administration of $400 \mu \mathrm{g}$ of albuterol (Ventolin, GlaxoSmithKline) via a metered-dose inhaler. Changes in the FEV1 were expressed as 1) An absolute change relative to the baseline $(\triangle \mathrm{FEV} 1)$ and 2$)$ A percentage change relative to the baseline ( $\triangle \mathrm{FEV} 1 \%$ baseline). Changes in the FVC were expressed in a similar manner. Predicted values of spirometry were calculated from the reference equations published by Zheng and Zhong. ${ }^{14}$ The bronchodilator test was considered significant if an increase in either $\mathrm{FEV} 1$ or $\mathrm{FVC} \geq 12 \%$ was observed and $\geq 200 \mathrm{~mL}$ as an absolute value compared with the baseline. ${ }^{15}$

Blood Eosinophil counts (EOS): Blood eosinophil and total white blood cell counts were obtained by blood routine test using an Automated Cell Counter (Sysmex, Kobe, Japan).

Before the above tests, both physician and examination operator should inquire the patients smoking history and verify the patients had no medication history within 3 days as bronchodilators, corticosteroids. All three tests were performed on the same day. Otherwise, patients were excluded from this study. 


\section{Study Design}

Based on a previous study which is about Exhaled nitric oxide, systemic inflammation, and the spirometry response to inhaled fluticasone propionate in severe COPD patients. ${ }^{16}$ We assumed a population mean of pre-bronchodilator $\mathrm{FVC}$ is $2.61 \mathrm{~L}$ and sample mean is $2.44 \mathrm{~L}$. The study was powered (alpha of 0.05 and beta of 0.20 ) for pre-bronchodilator FVC and the change in FVC after the administration of $400 \mu \mathrm{g}$ of albuterol to detect this difference with a level of confidence of $95 \%$. This resulted in a sample size calculation of 169 patients, allowing for $20 \%$ of consented subjects to either fail spirometry screening.

All of the 346 COPD patients were divided into two groups according to the FVC changes in response to albuterol administration including: (I) positive FVC group (PFVC): Patients with $\triangle \mathrm{FVC} \geq 200 \mathrm{~mL}$ and $\Delta \mathrm{FVC} \%$ baseline $\geq 12 \%$; (II) negative FVC group (NFVC): referring to the rest of the patients without significant responsiveness in terms of FVC. Next, patients with $\triangle F E V 1 \geq 200 \mathrm{~mL}$ and $\triangle \mathrm{FEV} 1 \%$ baseline $\geq 12 \%$ were excluded and the remaining 180 patients then were separated into two groups in a similar way: (I) pure positive FVC group (PPFVC): composed of patients with $\triangle \mathrm{FVC} \geq 200 \mathrm{~mL}$ and $\triangle \mathrm{FVC} \%$ baseline $\geq 12 \%$ without significant responsiveness with respect to FEV1; (II) negative FVC-negative FEV1 group (NNFVC): comprised of patients without significant responsiveness neither in terms of FVC nor FEV1.

The study was approved by the Shandong Provincial Hospital Affiliated to Shandong University Ethics Committee (No. 2016-23). This action did not produce any potential harm to patients. This operation was strictly obeyed with the Helsinki Declaration. All patients have signed an informed consent. All patient information was kept confidential.

\section{Statistical Analysis}

The data were analyzed using the SPSS 22.0 software (SPSS Inc., Chicago, IL, USA). Qualitative variables were expressed as proportions and numbers, whereas quantitative variables were expressed as median (interquartile range, IQR) (non-normal distribution). Comparisons between PFVC and NFVC, PPFVC and NNFVC were investigated using the Mann-Whitney $U$-test or $\chi^{2}$-square test where appropriate. The Spearman correlation was used to evaluate the relationships between the FeNO concentration and bronchodilator responsiveness vis-a-vis FVC and FEV1. Receiver operating characteristic curves were generated for selected cutoff values of bronchodilator responsiveness in terms of FVC to detect high FeNO values. $\mathrm{P}<0.05$ was considered statistically significant.

\section{Results}

\section{Baseline Characteristics of COPD Patients with or Without Significant Responsiveness in Terms of FVC}

All the 346 patients with COPD were recruited in this study, the mean age was $59.3 \pm 10.5$ years, $232(67.1 \%)$ were males and $114(32.9 \%)$ were females. The mean age, sex, and body mass index (BMI) were similar within each subgroup. Patients with significant responsiveness related to the $\mathrm{FVC}$ had lower baseline $\mathrm{FVC}$ values, FEV1 values, FEV1/FVC ratios, forced expiratory flows at $75 \%$ of the FVC (MEF75), forced expiratory flows at $50 \%$ of the FVC (MEF50), forced expiratory flows at $25 \%$ of the FVC (MEF25), maximal mid-expiratory flows (MMEF), and higher baseline residual volume/total lung capacity (RV/TLC) ratios, compared with who were without significant $\mathrm{FVC}$ responsiveness $(\mathrm{Z}=-5.042$ to $-0.375, \mathrm{p}=0.000-0.008)$ (Table 1).

\section{FeNO Levels and Blood Eosinophil Counts of Patients with or Without Significant Responsiveness in Terms of FVC}

A significant difference in FeNO values was observed between the subgroups (Figure 1). For the entire cohort, FeNO levels in patients with significant $\mathrm{FVC}$ responsiveness were significantly higher than the NFVC group $(Z=-2.284$, $\mathrm{p}=0.022$ ); Similar tendency on parameters was observed in the PPFVC and NNFVC groups $(\mathrm{Z}=-2.588, \mathrm{p}=0.010)$ (Table 1).

There is no significant discrepancy observed regarding the blood eosinophil counts between the subgroups (Table 1).

\section{Cut-off Values of FVC Responsiveness Used to Detect High FeNO Levels}

For the entire sample (NFVC and PFVC groups), positive correlation was depicted between $\mathrm{FeNO}$ and $\triangle \mathrm{FVC}(\mathrm{r}=0.216$, $\mathrm{P}=0.000), \Delta \mathrm{FVC} \%$ baseline $(\mathrm{r}=0.154, \mathrm{P}=0.004)$ (Figure 2). The correlation between FeNO and $\triangle \mathrm{FEV} 1 \quad(\mathrm{r}=0.071$, $\mathrm{P}=0.186)$ or $\triangle \mathrm{FEV} 1 \%$ baseline $(\mathrm{r}=0.040, \mathrm{P}=0.459)$ were not significant. Excluded the patients with significant responsiveness in terms of FEV1, concerning the NNFVC and PPFVC groups, linear relationships between $\mathrm{FeNO}$ levels and $\triangle \mathrm{FVC}$ $(\mathrm{r}=0.251, \mathrm{P}=0.001), \Delta \mathrm{FVC} \%$ baseline $(\mathrm{r}=0.190, \mathrm{P}=0.011)$ 
Table I The Clinical Characteristics of COPD Patients

\begin{tabular}{|c|c|c|c|c|c|c|}
\hline Variables & NFVC & PFVC & p-value & NNFVC & PPFVC & p-value \\
\hline Sex (male/female) & $112 / 49$ & $120 / 65$ & $0.353^{\mathrm{a}}$ & $79 / 35$ & $43 / 23$ & $0.566^{\mathrm{a}}$ \\
\hline Age, years & $59.0(14.0)$ & $61.0(12.5)$ & $0.456^{\mathrm{b}}$ & $62.0(14.3)$ & $64.0(14.0)$ & $0.075^{\mathrm{b}}$ \\
\hline $\mathrm{BMI}, \mathrm{kg} / \mathrm{m}^{2}$ & $24.61(5.75)$ & $24.04(4.67)$ & $0.165^{\mathrm{b}}$ & $23.26(5.33)$ & $23.43(5.82)$ & $0.149^{\mathrm{b}}$ \\
\hline Smoking history (current/ex-/non-) & $75 / 28 / 58$ & $83 / 35 / 67$ & $0.834^{\mathrm{b}}$ & $62 / 21 / 31$ & $37 / 13 / 16$ & $0.750^{\mathrm{b}}$ \\
\hline BBD FEVI, L & $1.59(0.89)$ & I.I7(0.74) & $<0.001^{\mathrm{b}}$ & $1.54(1.10)$ & $1.0(0.73)$ & $<0.001^{\mathrm{b}}$ \\
\hline BBD FEVI, \%pred & $59.2(26.6)$ & $47.65(24.2)$ & $<0.001^{b}$ & $60.35(26.5)$ & $46.3(27.7)$ & $<0.001^{b}$ \\
\hline ABD FEVI, L & $1.70(0.98)$ & $1.45(0.87)$ & $0.002^{\mathrm{b}}$ & $1.63(1.06)$ & $1.16(0.64)$ & $<0.001^{\mathrm{b}}$ \\
\hline ABD FEVI, \%pred & $65.22(24.06)$ & $57.80(28.15)$ & $0.023^{b}$ & $65.20(23.98)$ & $52.95(28.63)$ & $0.001^{\mathrm{b}}$ \\
\hline$\Delta$ FEVI, L & $0.15(0.18)$ & $0.24(0.17)$ & $<0.001^{b}$ & $0.10(0.12)$ & $0.15(0.07)$ & $0.001^{\mathrm{b}}$ \\
\hline$\Delta \mathrm{FEVI}, \%$ baseline & $8.60(10.50)$ & $21.90(16.00)$ & $<0.001^{b}$ & $6.85(6.20)$ & $12.05(10.90)$ & $<0.001^{\mathrm{b}}$ \\
\hline BBD FVC, L & $2.89(1.30)$ & $2.47(0.98)$ & $<0.001^{b}$ & $2.73(1.53)$ & $2.11(1.32)$ & $<0.001^{\mathrm{b}}$ \\
\hline BBD FVC, \%pred & $86.00(21.80)$ & $75.10(24.50)$ & $<0.001^{b}$ & $86.25(20.10)$ & $69.35(30.40)$ & $<0.001^{\mathrm{b}}$ \\
\hline ABD FVC, $L$ & $2.99(1.26)$ & $2.97(1.15)$ & $0.725^{\mathrm{b}}$ & $2.86(I .43)$ & $2.47(1.39)$ & $0.025^{\mathrm{b}}$ \\
\hline ABD FVC, \%pred & $88.29(23.4 I)$ & $91.27(25.27)$ & $0.083^{b}$ & $87.81(22.89)$ & $83.18(35.39)$ & $0.491^{\mathrm{b}}$ \\
\hline$\Delta \mathrm{FVC}, \mathrm{L}$ & $0.13(0.17)$ & $0.47(0.27)$ & $<0.001^{b}$ & $0.13(0.17)$ & $0.36(0.19)$ & $<0.001^{b}$ \\
\hline$\Delta \mathrm{FVC}$, \%baseline & $5.00(6.40)$ & $17.75(11.00)$ & $<0.001^{b}$ & $4.35(6.50)$ & $16.50(8.00)$ & $<0.00 \mathrm{I}^{\mathrm{b}}$ \\
\hline BBD FEVI/FVC, \% & $55.35(\mid 7.43)$ & $49.13(17.98)$ & $<0.001^{b}$ & $57.04(18.65)$ & $48.10(16.23)$ & $0.002^{\mathrm{b}}$ \\
\hline ABD FEVI/FVC, \% & $59.54(\mid 5.58)$ & $51.53(18.89)$ & $<0.001^{b}$ & $60.06(17.06)$ & $48.18(17.87)$ & $<0.001^{\mathrm{b}}$ \\
\hline BBD MEF75, L/S & $1.95(1.85)$ & $1.25(1.34)$ & $<0.001^{b}$ & $1.98(2.44)$ & $1.06(1.19)$ & $<0.001^{\mathrm{b}}$ \\
\hline BBD MEF75, \%pred & $30.80(27.90)$ & $20.70(19.60)$ & $<0.001^{b}$ & $33.15(33.50)$ & $18.40(20.80)$ & $<0.001^{\mathrm{b}}$ \\
\hline BBD MEF50, L/S & $0.82(0.80)$ & $0.6 I(0.59)$ & $<0.001^{\mathrm{b}}$ & $0.84(1.00)$ & $0.46(0.54)$ & $<0.001^{b}$ \\
\hline BBD MEF50, \%pred & $21.20(19.00)$ & $16.15(15.40)$ & $<0.001^{b}$ & $21.60(22.30)$ & $13.15(11.60)$ & $<0.00 \mathrm{I}^{\mathrm{b}}$ \\
\hline BBD MEF25, L/S & $0.24(0.22)$ & $0.24(0.18)$ & $0.289^{b}$ & $0.23(0.27)$ & $0.22(0.16)$ & $0.290^{\mathrm{b}}$ \\
\hline BBD MEF25, \%pred & $17.80(16.00)$ & $18.00(13.00)$ & $0.626^{\mathrm{b}}$ & $19.90(\mid 8.20)$ & $19.25(\mid 3.60)$ & $0.707^{\mathrm{b}}$ \\
\hline BBD MMEF, L/S & $0.61(0.58)$ & $0.48(0.47)$ & $0.002^{b}$ & $0.62(0.66)$ & $0.37(0.39)$ & $0.001^{\mathrm{b}}$ \\
\hline BBD MMEF, \%pred & $19.20(16.70)$ & $15.85(\mid 4.00)$ & $0.004^{b}$ & $19.45(19.80)$ & $13.35(\mid 3.40)$ & $0.003^{b}$ \\
\hline BBD RV/TLC \% & $46.85(11.10)$ & $52.13(10.71)$ & $<0.001^{\mathrm{b}}$ & $46.85(10.87)$ & $55.58(8.2 I)$ & $<0.001^{b}$ \\
\hline BBD RV/TLC, \%pred & $127.60(25.20)$ & $136.80(30.50)$ & $0.008^{b}$ & $123.55(20.20)$ & $140.80(27.20)$ & $0.001^{\mathrm{b}}$ \\
\hline FeNO, ppb & $41.00(32.00)$ & $46.00(48.80)$ & $0.022^{\mathrm{b}}$ & $41.00(29.50)$ & $50.00(42.00)$ & $0.010^{\mathrm{b}}$ \\
\hline EOS, $10^{9} / \mathrm{L}$ & $0.14(0.18)$ & $0.16(0.27)$ & $0.160^{b}$ & $0.12(0.16)$ & $0.13(0.23)$ & $0.689^{\mathrm{b}}$ \\
\hline EOS\%, \% & $1.95(2.80)$ & $2.10(3.60)$ & $0.522^{\mathrm{b}}$ & $1.90(2.70)$ & $1.80(2.40)$ & $0.988^{\mathrm{b}}$ \\
\hline$E O S \geq 2 \% / E O S<2 \%$ & $81 / 80$ & $100 / 85$ & $0.487^{b}$ & $54 / 60$ & $32 / 34$ & $0.885^{\mathrm{b}}$ \\
\hline
\end{tabular}

Notes: Values are median (interquartile range). ${ }^{a}$ Analyzed by Chi-square test; ${ }^{b}$ Analyzed by Mann-Whitney's U-test.

Abbreviations: BMI, body mass index; Smoking history (current/ex-/non-), current-smokers, ex-smokers, non-smoking; BBD, before bronchodilator; ABD, after bronchodilator; FVC, forced vital capacity; FEVI, forced expiratory volume in one second; MEF75, forced expiratory flow at $75 \%$ of the FVC; MEF50, forced expiratory flow at $50 \%$ of the FVC; MEF25, forced expiratory flow at $25 \%$ of the FVC; MMEF, maximal mid-expiratory flow; RV, residual volume; TLC, total lung capacity; $\triangle$, absolute change relative to baseline; Pred, predicted; FeNO, fractional exhaled nitric oxide; ppb, parts per billion; EOS, blood eosinophils absolute count; EOS\%, blood eosinophils percentage count; PFVC, positive FVC group, COPD patients with significant responsiveness in terms of $F V C(\triangle F V C \geq 200 \mathrm{~mL}$ and $\triangle F V C \%$ baseline $\geq I 2 \%)$ regardless of $F E V I$; NFVC, negative FVC group, COPD patients without significant responsiveness in terms of FVC regardless of FEVI.PPFVC, pure positive FVC group, COPD patients with significant responsiveness in termx of FVC, but without significant responsiveness in term of FEVI ( $\triangle F E V I \geq 200 \mathrm{~mL}$ and $\triangle \mathrm{FEVI} \%$ baseline $\geq 12 \%$; $\mathrm{NNFVC}$, negative FVCnegative FEVI group, COPD patients without significant responsiveness neither in term of FVC nor in terms of FEVI.

(Figure 2) were equally noticed. Meanwhile, the relationships between FeNO and $\triangle \mathrm{FEV} 1(\mathrm{r}=-0.002, \mathrm{P}=0.980)$ or $\triangle$ FEV $1 \%$ baseline $\quad(\mathrm{r}=-0.047, \quad \mathrm{P}=0.535)$ were also no difference.

Regarding the NNFVC and PPFVC groups population, the area under the receiver operating characteristic curve (AUC) for detecting FeNO levels $\geq 25$ parts per billion (ppb) with $\triangle F V C$ was calculated as $0.701(\mathrm{p}=0.010)$, the AUC for detecting FeNO levels $\geq 50 \mathrm{ppb}$ with $\triangle F V C$ was determined to be $0.623(p=0.005)$ (Figure 3$)$. The $\triangle F V C$ cutoff values with the best sensitivity and specificity were selected according to the Youden index: $0.165 \mathrm{~L}$ of $\triangle \mathrm{FVC}$ with a sensitivity of $61.8 \%$ and a specificity of $86.7 \%$ for detecting FeNO levels $\geq 25 \mathrm{ppb}, 0.205 \mathrm{~L}$ of $\triangle \mathrm{FVC}$ with a sensitivity of $61.1 \%$ and a specificity of $63.9 \%$ for detecting FeNO levels $\geq 50 \mathrm{ppb}$.

\section{Discussion}

This study's principal finding can be stated as follows: 1) FeNO concentrations in COPD patients were significantly 


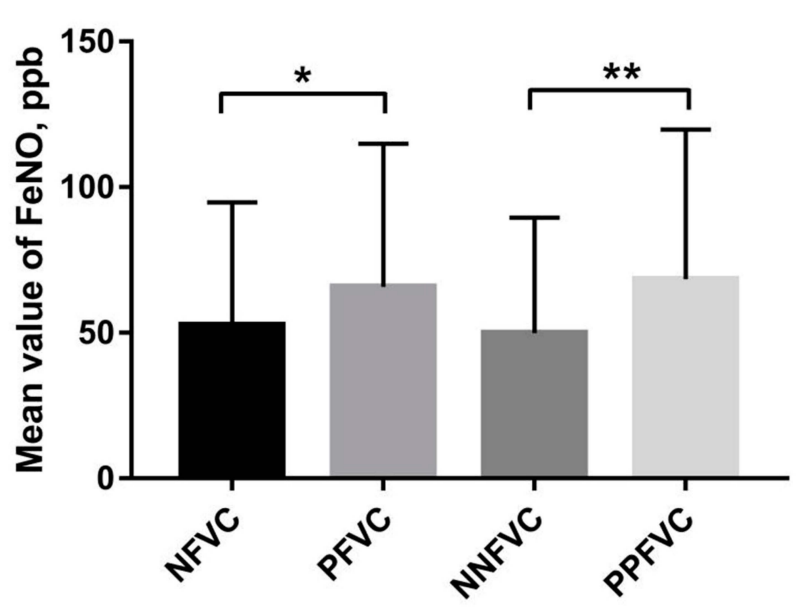

Subgroup in COPD patients by FVC

Figure I The distribution of FeNO mean value among respondents. Notes: $* \mathrm{P}<0.05 ; * * \mathrm{P}<0.05$.

Abbreviations: NFVC, negative FVC group; PFVC, positive FVC group; NNFVC, negative FVC-negative FEVI group; PPFVC, pure positive FVC group.

and positively correlated with $\triangle \mathrm{FVC} ; 2)$ The application of bronchodilator responsiveness in terms of FVC to detect high FeNO levels in COPD cases is a comparatively simple method with relatively high sensitivity and specificity; 3) FVC responders exhibited poorer baseline lung functions than non-responders. Chen et al reported that $\mathrm{RV} / \mathrm{TLC} \%$ predictions were positively correlated with $\triangle \mathrm{FVC}(\mathrm{r}=0.386)$ and $\triangle \mathrm{FVC} \%$ baseline $(\mathrm{r}=0.495)$, using of FVC bronchodilator responsiveness in detecting hyperinflation in COPD patients demonstrated high sensitivities and specificities. ${ }^{8}$ As showed in this study, RV/TLC values were elevated and were found to be higher in FVC responders than non-responders. This may be partly accounted for by the higher degree of hyperinflation, which airway obstruction made, in FVC responders.

COPD patients on the mild side of the severity spectrum differ from those on the severe side regarding the relation between their FEV1 and FVC responses to bronchodilator inhalation. Bronchodilator response of advanced lung function parameters depends on COPD severity. ${ }^{17}$ In more severe cases of COPD patients, FVC remarkably rises after bronchodilator administration whereas FEV1 remains substantially constant, ${ }^{7}$ isolated volume response to bronchodilators is a characteristic of severe emphysema in COPD patients. ${ }^{6,9,18}$ In other words, FVC responders may suffer from more severe airway hyperresponsiveness, airway obstruction, and emphysema. It is well known that COPD is an inflammatory disease affecting both the airways and the lungs, which induces the release of numerous proinflammatory cytokines and mediators. This cascade of events might include the synthesis of induced nitric oxide synthase (iNOS) by macrophages, epithelium, and vascular smooth muscles in the airway. ${ }^{19}$ We speculated that FVC responders with more severe airway hyperresponsiveness, airway obstruction, and emphysema sustained more severe airway inflammation or airway eosinophilic inflammation which in turn elevated their FeNO levels, considering that excessive inflammation plays an important pathophysiologic role in the progress of COPD. The magnitude of change in the FVC after bronchodilator administration may to some extent reflect the degree of the undergoing inflammatory process in COPD. Another possible explanation is the decreased pulmonary diffusing capacity of NO due to irreversible structural defects caused by emphysema. ${ }^{20,21}$

Airway inflammation is a consistent feature of COPD. Despite the fact that neutrophilic infiltration is the most common inflammatory phenotype in COPD, eosinophilic infiltration does exist in a subset of COPD patients, even after the careful exclusion of patients with any features of asthma. ${ }^{22}$ Singh et al revealed that $37 \%$ of COPD patients have eosinophilic airway inflammation. ${ }^{23}$ One possible explanatory hypothesis is that smoking and other mechanisms that recruit neutrophils into the airway mucosa in COPD also cause a certain degree of eosinophil influx. ${ }^{22}$ Furthermore, these patients exhibit the greater response to corticosteroid therapy. ${ }^{22,24}$ Eosinophilic COPD appears to be a distinct patient subgroup with an increased corticosteroid response and better prognoses. ${ }^{23}$

Identifying COPD patients with an eosinophilic inflammation may be of great help in COPD management. A positive correlation between FeNO levels and eosinophilia has been confirmed in induced sputum and bronchoalveolar lavage. ${ }^{25}$ Additionally, it has been considered a marker for eosinophilic airway inflammation, especially in asthma. ${ }^{25}$ For COPD, similar outcomes have been demonstrated in previous researches. ${ }^{26,27}$ But considered convenience and comfort for patients, a safe and simple test to reflex the inflammatory type and level is necessary. So, the research about the relationship between FVC and FeNO had a practical meaning. Soter et al proved that $\mathrm{FeNO}$ values were reliable surrogate markers of eosinophilic inflammation in COPD patients. There was a significant positive correlation between the percentage of sputum eosinophils and FeNO concentrations both during exacerbations $(\mathrm{r}=0.593, \mathrm{p}<0.001)$ and hospital discharge $(\mathrm{r}=0.337, \mathrm{p}=0.044) .{ }^{26} \mathrm{FeNO}$ had a positive relationship with COPD severity and eosinophilic inflammation level. ${ }^{28,29}$ Moreover, COPD patients with higher levels of FeNO had a better responsiveness to corticosteroid therapy. ${ }^{27,30} \mathrm{In}$ 

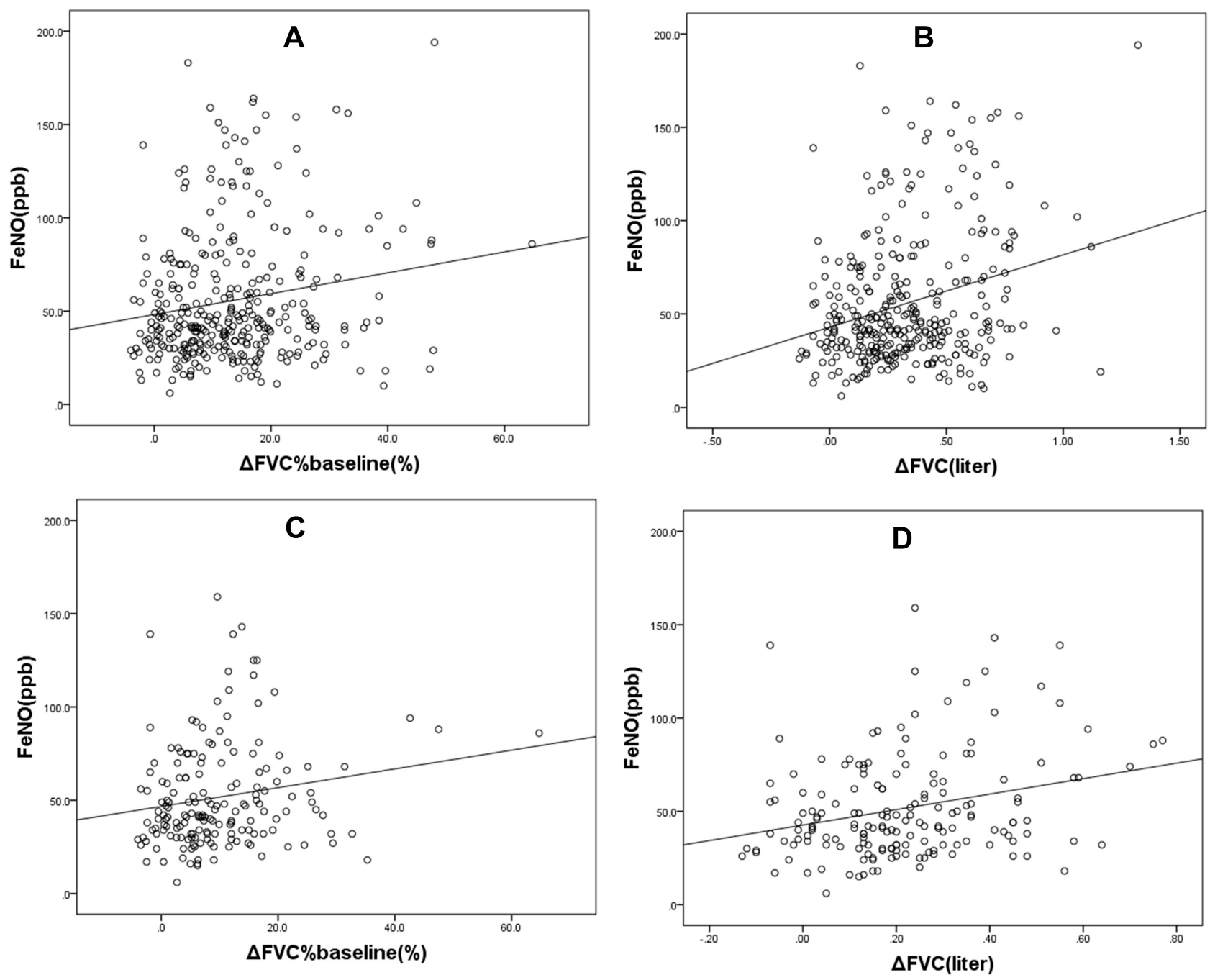

Figure 2 Scatter diagrams for FeNO levels versus $\triangle \mathrm{FVC} \%$ baseline, $\triangle \mathrm{FVC}$ : (A, B) entire cohort; (C, D) the population after the exclusion of patients with significant responsiveness in terms of FEVI $(\triangle \mathrm{FEVI} \geq 200 \mathrm{~mL}$ and $\triangle \mathrm{FEVI} \%$ baseline $\geq 12 \%$ ).

Abbreviations: FVC, forced vital capacity; FEVI, forced expiratory volume in one second; $\Delta$, absolute change relative to baseline; $\Delta \%$ baseline, percentage change relative to baseline; FeNO, fractional exhaled nitric oxide; ppb, parts per billion.

summary, FeNO measurements in COPD patients may help to improve the classification of patients into the aforementioned subclinical categories and promote more personalized treatment regimens. ${ }^{31}$

Frankly, there some limitations in this study. FeNO levels in our data seem higher than in previous studies. ${ }^{32}$ One explanation for this disparity may be the variations in population samples. As high as $52.3 \%(181 / 346)$ of patients in this study had peripheral blood eosinophil counts $\geq 2 \%$. Due to this study's shortage of clinical data, it is possible that its cohort included some patients with the so-called "AsthmaCOPD overlap" phenotype. ${ }^{33}$ It may be one reason for higher FeNO concentrations and higher eosinophil counts percent. One thing to note, there is no difference between NFVC and PFVC (or NNFVC and PPFVC) group in EOS indicators.
We think COPD is airway inflammatory disease, it would display the lesion locally first and significant, compared with general lesion, so the change of FVC or FeNO would be more evident than peripheral blood eosinophil counts. In the next research we will cover this limitation and observe the relationship between airway eosinophilic inflammation level and airway obstruction and iNOS. Besides, FeNO measurements can be affected by a number of factors, including different smoking histories, inhaled corticosteroid use, diet, different methodologies for measurement of exhaled NO levels, anthropometric variables, and so on. ${ }^{34}$ All the above factors might induce variability and limit the comparison between studies. We will pay more attention on the COPD rat model to detect the iNOS level, eosinophil counts in airway epithelium and smooth muscle, test the lung function 

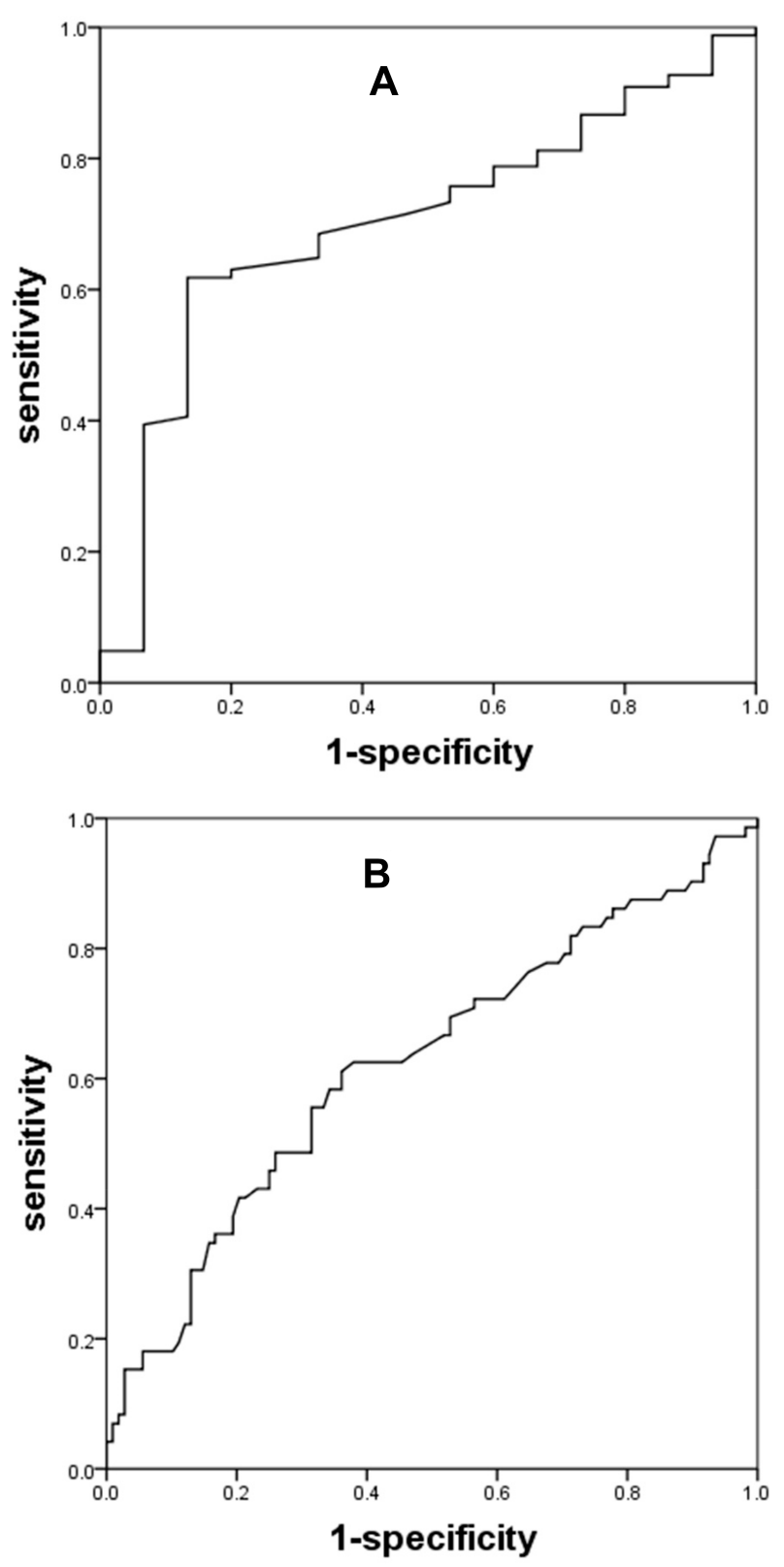

Figure 3 Receiver operating characteristic curves for detecting high FeNO level in patients with chronic obstructive pulmonary disease. (A) FeNO $\geq 25 p p b$; (B) $\mathrm{FeNO} \geq 50 \mathrm{ppb}$.

Abbreviations: FeNO, fractional exhaled nitric oxide; ppb, parts per billion.

of COPD rat model, study the mechanism of role of iNOS in airway hyperresponsiveness, airway obstruction, and emphysema in further research.

\section{Conclusion}

In conclusion, as far as we know this is the first time that linear relationships were demonstrated between FeNO levels and FVC responsiveness to bronchodilators. Since FeNO is useful for identifying eosinophilic inflammation responding better to corticosteroid therapy, these data may have pertinent implications for the management of COPD patients. Considering the relationship between $\triangle \mathrm{FVC}$ and emphysema, FVC responders may be identified as a different group of COPD patients. The usefulness of the bronchodilator test with respect to the FVC in the clinical management of COPD should be evaluated.

\section{Disclosure}

The authors report no conflicts of interest in this work.

\section{References}

1. Singh D, Agusti A, Anzueto A, et al. Global strategy for the diagnosis, management, and prevention of chronic obstructive lung disease: the GOLD science committee report 2019. Eur Respir J. 2019;53(5):1900164. doi:10.1183/13993003.00164-2019

2. Mathers CD, Loncar D. Projections of global mortality and burden of disease from 2002 to 2030. PLoS Med. 2006;3(11):e442. doi:10.1371/ journal.pmed.0030442

3. Vestbo J, Anderson W, Coxson HO, et al. Evaluation of COPD longitudinally to identify predictive surrogate end-points (ECLIPSE). Eur Respir J. 2008;31(4):869-873. doi:10.1183/09031936.00111707

4. Han MK, Agusti A, Calverley PM, et al. Chronic obstructive pulmonary disease phenotypes: the future of COPD. Am J Respir Crit Care Med. 2010;182(5):598-604. doi:10.1164/rccm.200912-1843CC

5. Burgel PR, Paillasseur JL, Caillaud D, et al. Clinical COPD phenotypes: a novel approach using principal component and cluster analyses. Eur Respir J. 2010;36(3):531-539. doi:10.1183/09031936.00175109

6. O'Donnell DE, Forkert L, Webb KA. Evaluation of bronchodilator responses in patients with "irreversible" emphysema. Eur Respir J. 2001;18(6):914-920. doi:10.1183/09031936.01.00216501

7. Schermer T, Heijdra Y, Zadel S, et al. Flow and volume responses after routine salbutamol reversibility testing in mild to very severe COPD. Respir Med. 2007;101(6):1355-1362. doi:10.1016/j.rmed.2006.09.024

8. Chen C, Jian W, Gao Y, Xie Y, Song Y, Zheng J. Early COPD patients with lung hyperinflation associated with poorer lung function but better bronchodilator responsiveness. Int J Chron Obstruct Pulmon Dis. 2016;11:2519-2526. doi:10.2147/copd.S110021

9. Quanjer PH, Ruppel GL, Langhammer A, et al. Bronchodilator response in FVC is larger and more relevant than in FEV1 in severe airflow obstruction. Chest. 2017;151(5):1088-1098. doi:10.1016/j. chest.2016.12.017

10. Exhaled NO. ATS/ERS recommendations for standardized procedures for the online and offline measurement of exhaled lower respiratory nitric oxide and nasal nitric oxide, 2005. Am J Respir Crit Care Med. 2005;171(8):912-930. doi:10.1164/rccm.200406-710ST

11. Miller MR, Hankinson JA, Brusasco V, et al. Standardisation of spirometry. Eur Respir J. 2005;26(2):319-338. doi:10.1183/09031 936.05.00034805

12. Wanger J, Clausen JL, Coates A, et al. Standardisation of the measurement of lung volumes. Eur Respir J. 2005;26(3):511-522. doi:10.1183/09031936.05.00035005

13. Macintyre N, Crapo RO, Viegi G, et al. Standardisation of the single-breath determination of carbon monoxide uptake in the lung. Eur Respir J. 2005;26(4):720-735. doi:10.1183/09031936.05.000 34905

14. Zheng J, Zhong N. Normative values of pulmonary function testing in Chinese adults. Chin Med J (Engl). 2002;115(1):50-54.

15. Pellegrino R, Viegi G, Brusasco V, et al. Interpretative strategies for lung function tests. Eur Respir J. 2005;26(5):948-968. doi:10.1183/ 09031936.05.00035205 
16. Kunisaki KM, Rice KL, Janoff EN, Rector TS, Niewoehner DE. Exhaled nitric oxide, systemic inflammation, and the spirometric response to inhaled fluticasone propionate in severe chronic obstructive pulmonary disease: a prospective study. Ther Adv Respir Dis. 2008;2(2):55-64. doi:10.1177/1753465808088902

17. Jarenback L, Eriksson G, Peterson S, Ankerst J, Bjermer L, Tufvesson E. Bronchodilator response of advanced lung function parameters depending on COPD severity. Int J Chron Obstruct Pulmon Dis. 2016;11:2939-2950. doi:10.2147/copd.S111573

18. Cerveri I, Pellegrino R, Dore R, et al. Mechanisms for isolated volume response to a bronchodilator in patients with COPD. J Appl Physiol (1985). 2000;88(6):1989-1995. doi:10.1152/jappl.2000.88.6.1989

19. Brindicci C, Kharitonov SA, Ito M, et al. Nitric oxide synthase isoenzyme expression and activity in peripheral lung tissue of patients with chronic obstructive pulmonary disease. Am J Respir Crit Care Med. 2010;181(1):21-30. doi:10.1164/rccm.200904-0493OC

20. Yang X, Tang X, Cao Y, et al. The bronchiectasis in COPD-OSA overlap syndrome patients. Int J Chron Obstruct Pulmon Dis. 2020;15:605-611. doi:10.2147/copd.S243429

21. Lu Z, Huang W, Wang L, Xu N, Ding Q, Cao C. Exhaled nitric oxide in patients with chronic obstructive pulmonary disease: a systematic review and meta-analysis. Int J Chron Obstruct Pulmon Dis. 2018;13:2695-2705. doi:10.2147/copd.S165780

22. Brightling CE, Monteiro W, Ward R, et al. Sputum eosinophilia and short-term response to prednisolone in chronic obstructive pulmonary disease: a randomised controlled trial. Lancet. 2000;356 (9240):1480-1485. doi:10.1016/s0140-6736(00)02872-5

23. Singh D, Kolsum U, Brightling CE, Locantore N, Agusti A, TalSinger R. Eosinophilic inflammation in COPD: prevalence and clinical characteristics. Eur Respir J. 2014;44(6):1697-1700. doi:10.1183/09031936.00162414

24. Leigh R, Pizzichini MM, Morris MM, Maltais F, Hargreave FE, Pizzichini E. Stable COPD: predicting benefit from high-dose inhaled corticosteroid treatment. Eur Respir J. 2006;27(5):964-971. doi:10.1183/09031936.06.00072105

25. Dweik RA, Boggs PB, Erzurum SC, et al. An official ATS clinical practice guideline: interpretation of exhaled nitric oxide levels (FENO) for clinical applications. Am J Respir Crit Care Med. 2011;184(5):602-615. doi:10.1164/rccm.9120-11ST
26. Soter S, Barta I, Antus B. Predicting sputum eosinophilia in exacerbations of COPD using exhaled nitric oxide. Inflammation. 2013;36 (5):1178-1185. doi:10.1007/s10753-013-9653-8

27. Gao J, Zhang M, Zhou L, et al. Correlation between fractional exhaled nitric oxide and sputum eosinophilia in exacerbations of COPD. Int J Chron Obstruct Pulmon Dis. 2017;12:1287-1293. doi:10.2147/copd.S134998

28. Lazar Z, Kelemen A, Galffy G, Losonczy G, Horvath I, Bikov A. Central and peripheral airway nitric oxide in patients with stable and exacerbated chronic obstructive pulmonary disease. J Breath Res. 2018;12(3):036017. doi:10.1088/1752-7163/aac10a

29. Tang B, Huang D, Wang J, Luo LL, Li QG. Relationship of blood eosinophils with fractional exhaled nitric oxide and pulmonary function parameters in chronic obstructive pulmonary disease (COPD) exacerbation. Med Sci Monit. 2020;26:e921182. doi:10.12659/ msm.921182

30. Dummer JF, Epton MJ, Cowan JO, et al. Predicting corticosteroid response in chronic obstructive pulmonary disease using exhaled nitric oxide. Am J Respir Crit Care Med. 2009;180(9):846-852. doi:10.1164/rccm.200905-0685OC

31. Alcazar-Navarrete B, Romero-Palacios PJ, Ruiz-Sancho A, RuizRodriguez O. Diagnostic performance of the measurement of nitric oxide in exhaled air in the diagnosis of COPD phenotypes. Nitric Oxide. 2016;54:67-72. doi:10.1016/j.niox.2016.02.003

32. Alcazar-Navarrete B, Ruiz Rodriguez O, Conde Baena P, Romero Palacios PJ, Agusti A. Persistently elevated exhaled nitric oxide fraction is associated with increased risk of exacerbation in COPD. Eur Respir J. 2018;51(1):1701457. doi:10.1183/13993003.014572017

33. Takayama Y, Ohnishi H, Ogasawara F, Oyama K, Kubota T, Yokoyama A. Clinical utility of fractional exhaled nitric oxide and blood eosinophils counts in the diagnosis of asthma-COPD overlap. Int J Chron Obstruct Pulmon Dis. 2018;13:2525-2532. doi:10.2147/ copd.S167600

34. Dressel H, de la Motte D, Reichert J, et al. Exhaled nitric oxide: independent effects of atopy, smoking, respiratory tract infection, gender and height. Respir Med. 2008;102(7):962-969. doi:10.1016/ j.rmed.2008.02.012

\section{Publish your work in this journal}

The International Journal of COPD is an international, peer-reviewed journal of therapeutics and pharmacology focusing on concise rapid reporting of clinical studies and reviews in COPD. Special focus is given to the pathophysiological processes underlying the disease, intervention programs, patient focused education, and self management protocols. This journal is indexed on PubMed Central, MedLine and CAS. The manuscript management system is completely online and includes a very quick and fair peer-review system, which is all easy to use. Visit http://www.dovepress.com/testimonials.php to read real quotes from published authors. 